\title{
ENSAYO/ESSAY
}

\section{PENSAMIENTO Y CORRESPONDENCIA DE JOSÉ MARTÍ AL DIARIO LA NACIÓN DE LA REPÚBLICA ARGENTINA}

Renée Isabel Mengo': Universidad Nacional de Córdoba. Argentina. hr-01@sinectis.com.ar

\section{RESUMEN}

Las letras hispanoamericanas, cobran dimensión especial cuando se trata de la obra de Martí, no sólo como poeta-escritor, sino también como periodista libertario de su tierra. Es la etapa de atención exclusiva a los asuntos cubanos. Su palabra escrita es combatiente, y con ella sacudirá conciencias en diarios como La Nación, cuyos reportajes expresan la libertad, el espíritu de trabajo y la oportunidad para todos y reflejan muchos aspectos de la sociedad norteamericana. Esto le ha llevado a ser considerado un periodista universal.

PALABRAS ClAVE: José Martí - La Nación - Periodista - Sociedad Norteamericana Cuba.

\footnotetext{
${ }^{1}$ Autor correspondiente:

Renée Isabel Mengo: Docente Adjunta en la Cátedra de Historia Social Contemporánea de la Universidad Nacional de Córdoba. Argentina.

Correo: hr-01@sinectis.com.ar
} 


\title{
THOUGHT AND CORRESPONDENCE OF JOSE MARTI TO THE JOURNAL LA NACIÓN OF ARGENTINA
}

\begin{abstract}
American letters charge special dimension when it comes to the work of Martí, not only as a poet-writer, but also as a libertarian land journalist. Stage is the exclusive focus on Cuban affairs. His written word is fighter, and with it he will shake consciences in newspapers such as The Nation, whose stories express the freedom, the spirit of work and opportunity for all and reflect many aspects of American society. This has led him to be considered a universal journalist.
\end{abstract}

KEYWORDS: Jose Marti - The Nation - Journalist - Society of America - Cuba.

\section{ANÁLISIS}

Las letras hispanoamericanas, cobran dimensión especial cuando se trata de la obra de Martí, no sólo como poeta-escritor, sino también como periodista libertario de su tierra, con proyección continental.

José Martí nació el 28 de enero de 1853 en La Habana, Cuba, donde transcurrió su niñez, adolescencia y parte de su juventud. Publica El Diablo Cojuelo y dirige el periódico Patria Libre, de matiz revolucionario (Marinello, 1977: 354 y 358), motivo de condena con sólo 18 años de edad (Schulz, 1968: 15 y 16), lo que fue cambiado por el destierro a España. Ese hecho, dará origen a las tres etapas de su vida, a saber:

I) 1871-1881: estancia en España, donde completa sus estudios y continúa publicando en pro de la liberación de su patria. Viajes a Francia, México y Centro América. Acumulación de experiencias. Deja en Cuba a su esposa e hijo.

II) 1881-1889: arriba a los EE.UU y comienzo de su gran preocupación que fue la organización del Partido Revolucionario cubano. Corresponde a la etapa de madurez y participación de los grandes conflictos que comenzaban a darse en el país del Norte.

III) 1889-1895: la guerra directa contra España y muerte en el combate de "Dos Ríos" el 19 de mayo de 1895.

Es la etapa de atención exclusiva a los asuntos cubanos. En todas ellas, su palabra escrita combatiente, derramará ideas y sacudirá conciencias. Unas veces como corresponsal en: La Opinión de Caracas, 1881; La Nación de Buenos Aires, 1882; El Partido Liberal, México, 1883; La República, Honduras, 1886 y La Opinión de Montevideo en 1887. Otras, dirigiendo La Patria Libre, La Habana, 1869; la Revista Venezolana, Caracas, 1881; la Edad de oro, New York; La Pluma, de Bogotá; el Almendares, La Habana. Las obras publicadas han hecho de Martí que se le considere un genuino periodista universal.

Con respecto a los aportes que hace al diario La Nación de Buenos Aires a partir de 
1882, (Marinello, 1977: 388) envía correspondencia desde New York, expresando la libertad, el espíritu de trabajo y la oportunidad para todos, como esencia de La Nación Americana.

A la vez, alerta sobre el afán desmedido de riqueza y el impacto que produjo el aluvión inmigratorio en aquel país, sosteniendo a veces pensamientos no muy optimistas al respecto. Así lo expresó en carta a La Nación el 4 de mayo de 1887 (Mestas, 1993: 64) "En los Estados Unidos Hierve ahora una nación nueva..." con el consiguiente conflicto social que ello daría lugar. También los daba a conocer en $L a$ Nación al decir en 1887 (o. c. 64). "Estamos en plena lucha entre capitalistas y obreros...". Este tema va a ser largamente publicado en el diario argentino, remarcando aquellos aspectos que le daban validez:... "La opresión es obvia, las demandas son sensatas..." que saldrían en dos números del 4 y 6 de junio de 1886 respectivamente. La huelga de los mineros de Reading en 1888 y la de los conductores de New York en 1889, recibieron especial atención en La Nación el 9 de marzo de 1888 y el 30 de marzo de 1889.

Paralelo a la acción ideológica y política, lo cultural siempre acompañó la vida de Martí, uno de esos acontecimientos fue el comentario que el poeta hace por la inauguración de la estatua de La Libertad de New York en 1887 (Marinello, 1977: 398).

\subsection{Fiestas de la Estatua de la Libertad (Fragmentos)}

Nueva York, octubre 29 de 1886.

Sr. Director de La Nación:

...Un cañonazo, un vuelo de campanas, una columna de humo fueron la bahía y ciudad de Nueva York desde que cerró la parada hasta que, al caer el crepúsculo, acabaron las fiestas en la isla donde se eleva el monumento.

iA encías desdentadas se asemejaban, diosa como la tempestad y amable como el cielo! Vuelven en su presencia los ojos secos a saber lo que son lágrimas. Parecía que las almas se abrían, y volaban a cobijarse en los pliegues de su túnica, a murmurar en sus oídos, a posarse en sus hombros, a morir, como las mariposas en su luz. Parecía viva; el humo de los vapores la envolvía; una vaga claridad la coronaba; lera en verdad como un altar, con los vapores arrodillados a sus pies! !Ni en el Apolo de Rodas, con la urna de fuego sobre su cabeza y la saeta de la luz en la mano, fue más alto! Ni el Júpiter de Fidias, todo de oro y marfil, hijo del tiempo en que aún eran mujeres los hombres. Ni la estatua de Sumnat de los hindúes, incrustada como su fantasía de piedras preciosas. Ni las dos estatuas sedantes de Tebas, cautivas como el alma del desierto en sus pedestales tallados. Ni los cuatro colosos que defienden, en la boca de la tierra, el templo de Ipsambul. Más grande que el San Carlos Bor romeo, de torpe bronce, en el cerro de Arona, junto al lago; más grande que la Virgen de Puy, concebida sin alas, sobre el monte que ampara al caserío; más grande que el Arminio de los Cheruskos, que se alza por sobre la puerta de Tautenberg citando con su espada las tribus germánicas para anonadar las legiones de Varus; más grande que 
la Germania de Niederwald, infecunda sienes, y tal como remata en cumbre el monte, toda la estatua, en lo alto de la antorcha, se condensa la luz.

Pequeña como una amapola lucía a los pies de la estatua la ancha tribuna, construida para celebrar la fiesta con pinos frescos y pabellones vírgenes. Los invitados más favorecidos ocupaban la explanada frente a la tribuna. La isla entera parecía un solo ser humano.

iNo se concibe cómo voceó este pueblo cuando su Presidente, nacido como él de la masa del trabajo, puso el pie en la lancha de honor para ir a recibir la imagen en que cada hombre se ve como redimido y encumbrado!

Sólo los estremecimientos de la tierra dan idea de explosión semejante.

El clamor de los hombres moría ahogado por el estampido de los cañones; de las calderas de las fábricas y los buques se exhalaba a la vez el vapor preso con un júbilo loco, conmovedor y salvaje; ya parecía el alma india, que pasaba a caballo por el cielo, con su clamor de guerra; ya que, sacudiendo al encorvarse las campanas todas, se arrodillaban las iglesias; ya eran débiles o estridentes, imitados por las chimeneas de los vapores, los cantos del gallo con que se simboliza el triunfo.

Se hizo pueril lo enorme; traveseaba el vapor en las calderas; jugueteaban por la neblina los remolcadores; azuzaba la concurrencia de los vapores a sus músicos; los fogoneros vestidos de oro por el resplandor del fuego, henchían de carbón las máquinas; por entre la nube de humo se veía a los marineros de la armada, de pie sobre las vergas.

En vano pedía silencio desde la tribuna, moviendo su sombrero negro de tres picos, el mayor general de los ejércitos americanos; ni la plegaria misma del sacerdote Storrs, perdida en la confusión, acalló el vocerío; pero Lesseps, Lesseps, con su cabeza de ochenta años desnuda, bajo la lluvia, supo domarlo. Jamás se olvidará aquel espectáculo magnífico. Más que de un paso, de un salto se puso en pie el gran viejo.

iAh, piadoso viejo!, antes de que se siente, premiado por los aplausos de sus enemigos mismos, rendidos y maravillados, démosle gracias allá, en la América que no ha tenido todavía su fiesta, porque recordó nuestros pueblos y pronunció nuestro nombre olvidado en el día histórico en que América consagró a la libertad: ¿pues quién sabe morir por ella mejor que nosotros?, ¿y amarla más?

"!Hasta luego, en Panamá!, donde el pabellón de las treinta y ocho estrellas de la América del Norte irá a flotar al lado de las banderas independientes de la América del Sur, y formará en el nuevo mundo, para el bien de la humanidad, la alianza pacifica y fecunda de la raza francolatina y de la raza anglosajona".

iBuen viejo que encanta a las serpientes!, !Alma clara, que nos ve lo grande del corazón bajo los vestidos manchados de sangre! !A ti, que hablaste de la libertad como si fuera tu hija, la otra América te ama! 
Y antes de que se levantara el senador Ewarts a ofrecer la estatua al presidente de los Estados Unidos en nombre de la Comisión americana, la concurrencia, conmovida por Lesseps, quiso saludar a Bartholdi, que con feliz modestia se levantó a dar las gracias al público desde su asiento en la tribuna. Nunca habla el senador Ewarts sin noble lenguaje y superior sentido, y es su elocuencia diestra y genuina, que va a las almas porque nace de ella.

Pero la voz se le apagaba cuando leía en páginas estrechas el discurso en que pinta, con frase llena de cintas y pompones, la generosidad de Francia.

Y después de Lesseps, parecía una caña abatida; ya en la cabeza no tiene más que frente; apenas puede abrirse paso la inspiración por su rostro enjuto y apergaminado; viste gabán, y lleva el cuello vuelto; le cubría la cabeza un gorro negro.

Y cuando inopinadamente, en medio de su discurso, creyeron llegada la hora de descorrer, como estaba previsto, el pabellón que cubría el rostro de la estatua, la flotilla, la ciudad, rompió en un grito unánime que parecía ir subiendo por el cielo como un escudo de bronce resonante: !Pompa asombrosa y majestad sublime!, inunca ante altar alguno se postró un pueblo con tanta reverencia!, !Los hombres pasmados de su pequeñez, se miraban al pie del pedestal, como si hubieran caído de su propia altura!; el cañón a lo lejos retemblaba; en el humo los mástiles se perdían; el grito, fortalecido, cubría el aire; la estatua, allá en las nubes, aparecía como una madre inmensa! (Schultz, 1968: 88-93).

Otros aspectos de la sociedad norteamericana, desconocidos hasta ese momento en Latinoamérica, también fueron tratados por Martí y enviados a los distintos periódicos de las jóvenes capitales del Continente. Así envía a La Nación el 21 de octubre de 1886, su impresión y rechazo hacia el anarquismo, expresando: "la violencia anarquista es innecesaria" (Mestas, 1993: 120)'

De todas sus ricas observaciones en EE.UU. en función de la República que esperaba levantar en Cuba, sostuvo: "En lo que tropieza, es necesario estudiar a éste pueblo para no tropezar como él".

Los años transcurridos fuera de su Patria, fueron compensados con la representación consular que en él hicieron los gobiernos de Uruguay en 1887 y los de Argentina y Paraguay en 1890. Es en este momento cuando se desarrollaba la Conferencia Panamericana de Wáshington (1889-90) prevaleciendo en su contenido "América para la humanidad" por encima de la fórmula estadounidense -América para los americanos-. La importancia de los debates, defendida por la República Argentina fue motivo de especiales publicaciones en La Nación.

\subsection{Crónicas de la Conferencia Internacional Americana el Congreso de Washington.}

Nueva York, 28 de septiembre de 1889.

Señor Director de La Nación: 
Estos días han sido de recepciones y visitas para los hispanoamericanos. Unos venían de Europa a presentar credenciales al Congreso que llaman aquí de Panamérica, aunque ya no será de toda, porque Haití, como que el gobierno de Wáshington exige que le den en dominio la península estratégica de San Nicolás, no muestra deseos de enviar sus negros elocuentes a la conferencia de naciones; ni Santo Domingo ha aceptado el convite, porque dice que no puede venir a sentarse a la mesa de los que piden a mano armada su bahía de Samaná, y en castigo de su resistencia le imponen derechos subidos a la caoba.

Del Paraguay nadie ha llegado, aunque se publicó que venía con poderes de él Alberto Nin, el caballero juicioso que mandan de Montevideo. En los hoteles hay va y viene, y muchos cumplidos a la hora de pasar por las puertas, que es cosa que denuncia por estos pueblos la gente castellana. En el teatro del Casino, de yeso dorado que parece con las luces morería de mucha riqueza, todas la cabezas se vuelven a la vez, descuidando las arias del "Tambor Mayor", para ver entrar en su palco, con un ramo de rosas rojas, y majestad de casa real, a una sudamericana de ojos negros. Para luego el estudio y el examen del Congreso de Panamérica y sus hilos. Ahora la tarjeta de visita, la llegada de los argentinos, el vapor que entra y el tren que se va: la crónica.

... Ya para el 20, cuando llegaron los delegados del Plata, estaban en Nueva York los representantes de nuestras repúblicas. Entraban en amistad los unos; otros no ponían interés en conocerse.

Los de alma americana, los velan a todos con placer igual. En algún momento padecían. !Qué!; ¿que volverán para la América los tiempos en que entró Alvarado el Rubio de Guatemala porque lo dejaron entrar los odios entre los quichés y los zutujiles? Se hablaba más de los países de la vecindad que de lo que andan lejos. Se preguntaba, con curiosidad mezclada a cierto asombro, pro los delegados de la Argentina. En la memoria se llevaban las listas. Sólo faltaba Amaral Valente, del Brasil; Bolet Peraza, el de Venezuela, que estaba al llegar de su paseo francés; Romero, que no vuelve aún de Paris; y el Uruguay, y los de la Argentina. Y se cambiaban datos breves de los delegados.

Matías Romero, el de México, es ministro residente en Wáshington de años atrás; cuando Grant cayó en miseria, él fue el que llevó a la casa el primer check; casó con norteamericana; escribe sin cesar, y no habla casi nunca; cree acaso que México está más seguro en la amistad vigilante con los Estados Unidos que en la hostilidad manifiesta; en su patria, nadie duda de él; en Wáshington, todos le tienen por amigo cordial, como fue quien empujó el brazo de Grant en los de los ferrocarriles; ahora lleva uniforme galoneado, y calzones hasta el tacón; hace quince años, cuando levantaba en México su casa, piedra a piedra, venía todas las mañanitas de su quinta, jinete en una muía, con sombrero alto de pelo, levitón castaño, cárter al brazo izquierdo, y pantalones que tenían más que hacer con las rodillas que con los calcañales; pues en política, el que no es brillante, ¿no ha de ser singular?; no se ha olvidado la gente de México, ni el señorío ni la chinaca, del sombrero alto de Matías Romero; el que andaba en muía llevó los ferrocarriles. Dos más vienen por México; el 
uno es José Limatour, hijo de rico, que no desmigajó a los pies de las bailarinas la fortuna que allegó su padre con el trabajo, ni la empleó en deshonrarse, sino en mostrarse capaz y digno de ella; el otro es uno de los patriarcas mexicanos, el caballero indio Juan Navarro, compañero de Prieto, de Ramírez, de Payno, de los Lerdo, de todos los fundadores; es el cónsul de México en Nueva York; perdió su gran fortuna, y vive feliz con otra mayor, que es la de no lamentarla.

...Por el gentío del puente se van abriendo paso hasta la biblioteca. Allí espera de pie un anciano noble, y entra a pocos instantes, con paso como de batalla, un joven vigoroso: el Sr. D. Manuel Quintana y Roque Sáenz Peña; pinedo, el secretario activo, presenta y acerca; Hugues y Flint ofrecen a los delegados trasladarse al guardacostas: "aunque tal vez estén más cómodos si no se trasbordan". No se trasbordan. Se tienden todas las manos para dar la bienvenida a un hombre de rostro abierto y de sonrisa franca: Alberto Nin, el delegado del Uruguay. Un cónsul busca en vano flores que ofrecer a la dama argentina, la esposa de Sáenz Peña. La llegada está prevista; la aduana no abrirá el equipaje; los comisionados del gobierno y el comercio han preparado coches; se puede ir en calma al puente, a ver cómo se entra en Nueva York, en día de lluvia fina.

Rodea la comisión a los viajeros. Uno va de éste a aquél, hablando ya de negocios. Otros dejan ver en el rostro la alegría: "Es un buque bonaerense". "En esa cabeza joven hay una mente de poder". "Es un Chesterfield". "El joven ha debido ser militar".

Nueva York, 11 de diciembre de 1889.

Señor Director de La Nación:

...En los debates sobre el sorteo de los vicepresidentes; de los secretarios; sobre el quórum; sobre la firma de las actas, había defendido su parecer con minuciosidad y tesón D. Manuel Quintana, delegado de la Argentina, que a Henderson, que con inoportuna chanza quiso como censurarle su ausencia del paseo, le respondió seco y erguido: "yo he estado donde me mandaba mi deber y donde me pareció mejor estar", que a uno de los delegados colombianos, en disputa sobre si debían llamarse acuerdos o decisiones los dictámenes de la conferencia, contesto así: "lo mismo es que se llamen acuerdos o decisiones u opiniones o pareceres, puesto que en nada pueden obligar a las delegaciones que disientan de ellos, ni a sus gobiernos"; que a Blaine, cuando le dijo, según cuentan: "en Boston dirían de usted por su figura, señor delegado, que era un rector de universidad", repuso, inclinándose, "en mis país, señor secretario, todos tenemos la misma figura". Unos tenían a puntillo excesivo el del delegado argentino, que en lo de menos importancia aparente hacía hincapié, sin ceder cuando creía estar en las prácticas y en la previsión, ni insistir cuando el aviso de la vigilancia continua había sido acaso su único propósito. Y otros creían que en una reunión de hombres de pueblos cordiales y caballerescos, y en quienes pudiera ser mayor, por la predicación hiperbólica y el ansia ciega de progreso, el entusiasmo por lo ejemplar del Norte que el conocimiento de lo temible de él, era necesidad urgente que, por algunos al menos, se extremase la confianza, sobre todo cuando parece que se pudo notar en los primeros días una como impaciencia de todo freno, y mal humor por toda demora, de parte de la delegación norteamericana, que su más 
sutil expresión debió sujetarse desde el nacer por el decoro de los pueblos que es acá uso desdeñar, si era descortesía, y por el cumplimiento de sus deberes, si se trataba de llevar asuntos de tal monta a la loca y como quien no ve. $Y$ hay razón para sospechar que éste fue el caso, y que el remedio fue bien puesto, porque los diarios que están cerca del secretario intentaron sofocar el "orador del congreso", como le llama el Export and Finance, con una campaña de ridículo y acusaciones de venir vendido los ingleses, y pinturas de cuando sacaba el sorteo, "serio como una lechuza", a todo lo que se ha sobrepuesto él manteniendo , sin atender a la invectiva, los puntos de práctica y de dogma en que es maestro sagaz, recabando con su elocuencia acerada y sencilla el asentimiento de sus colegas, abatiéndole la soberbi a algún norteño menos conocedor de cosas internacionales, y levantándose a proponer que se dejara el nombramiento de las comisiones al secretario de Estado.

Nueva York, 31 de marzo de 1890.

Señor Director de La Nación:

No es hora de reseñar, con los ojos en lo porvenir los actos y los resultados de la conferencia de naciones de América, ni de beber el vino de triunfo y augurar que del primer encuentro se han acabado los reparos entre las naciones limítrofes, o se le ha calzado el freno al rocín glotón que quisieran echarle a pacer por los predios fértiles de sus vecinos; ni cabe afirmar que en esta entrevista tímida, se han puesto ya los pueblos castellanos de América, en aquel acuerdo que sus destinos e intereses les imponen, y a que, en cuanto los llame una voz imparcial, han de ir con arrebato, los unos arrepentidos, a devolver lo que no les pertenece, para que el hermano los perdone y el mundo no les tache de pueblo ladrón; los otros a confesar que vale más resguardarse juntos de los peligros de afuera, y unirse antes de que el peligro exceda a la capacidad de sujetarlo, que desconfiar, por rencillas de villorrio, de los pueblos con quienes el extraño los mantiene desde los bastidores en disputa, u ostentar la riqueza salpicada de sangre que con la garra al cuello le han sacado al cadáver caliente del hermano. Los pueblos castellanos de América han de volverse a juntar pronto, donde se vea, o donde no se vea. El corazón se lo pide. Sofocan los más grandes rencores, y se nota que se violentan para acordarse de ellos, y obrar conforme a ellos, en la tierra extraña. La conferencia de naciones pudo ser, a valer los pueblos de América menos de lo que valen, la sumisión humillante y definitiva de una familia de repúblicas libres, más o menos desenvueltas, a un poder temible e indiferente, de apetitos gigantescos y objetos distintos. Pero ha sido, ya por el clamor del corazón, ya por el aviso del juicio, ya por alguna levadura de afuera, la antesala de una gran concordia. ¿A qué detalles indiscretos, y gacetilla prematura, si ésa es, después de mucho oír y palpar, la lección visible de la conferencia?

...Ni puede calcularse, por más que se le entrevea, el benéfico influjo de esta reunión de pueblos fraternales, sin preparación y sin intrigas, sobre aquellos que por arrogancia o avaricia hayan pecado, o estuvieran en riesgo de pecar, contra la fraternidad de los pueblos de América. Pero cuando el delegado argentino Sáenz Peña dijo, como quien reta, la última frase de su discurso sobre el Zollverein, la frase que es estandarte, y allí fue una barrera, "Sea América para la humanidad", todos, como agradecidos, se pusieron en pie, comprendieron lo que no se decía, y le tendieron las 
manos.

Wáshington, 18 de abril de 1890.

Señor Director de "a Nación:

...La Argentina, por su delegado Quintana, se puso en pie a explicar el proyecto. La voz mandaba, alta y aguda. Los generales en batalla no fundan sus órdenes. Mientras escribiesen un considerando, el enemigo les llevarla la trinchera. Se le vela el caballo al orador, los cascos nobles e impacientes, la crin revuelta. A sus espaldas, en un gran mapa del océano, le hacía como marco a la cabeza blanca el mar azul. Fulminaba y contendía. No era lo que decía ataque, sino respuesta; ni verba, sino sentido; ni fanfarronada perniciosa, sino indispensable altivez. El que muestra rodillas flacas, ya está en tierra. Ni hay que traer sobre si a un enemigo a quien no se puede derribar, ni que invitarlo a que se eche encima, con lo flojo de la oposición. Ni mayordomos de raza ajena, ni mayordomos de nuestra raza. No es cuestión de razas, sino de independencia o servidumbre. Ni pueblos fuertes rubios, para su beneficio y moral, sobre los pueblos meritorios y capaces de América; ni pueblos fuertes trigueños, para su poder injusto, sobre las naciones afligidas de la América del Sur. Y vertía, a modo de tajante, sus palabras, como si tuviese agrupadas al pie, defendiéndolas y guiándolas a las naciones afligidas. Las palabras, pocas. Los discursos están en el timbre y el espíritu. Ni flores de yeso ni universidades. La elocuencia era de aquella nacida del pensamiento vivo y claro; y del ajuste, como de espada a vaina, de la idea a la forma. Oían, de codos en la mesa, los delegados hispanoamericanos. Los del Norte no abejeaban: "Ante el derecho internacional americano" dice al romper, "no existen en América naciones grandes ni pequeñas; todas son igualmente soberanas e independientes; todas son igualmente dignas de consideración y de respeto".

"El arbitraje propuesto no es un pacto de abdicación, de vasallaje, ni de sometimiento; antes como después de celebrarlo, todas y cada una de las naciones americanas conservarán la dirección exclusiva de su destino político con absoluta prescindencia de los demás".

Nueva York, 3 de mayo de 1890.

Señor Director de La Nación:

Ya se van, aleccionados y silenciosos, los delegados que vinieron de los pueblos de América a tratar, por el convite de Wáshington, sobre las cosas americanas. Ya vuelven a Centroamérica los de los cinco países, más centroamericanos de lo que vinieron, porque al venir se veían de soslayo unos a otros, y ahora se van juntos como si comprendieran que este modo de andar les va mejor. Ya salen en las conversaciones poco a poco, sin la cautela de los días oficiales, las notas curiosas, los desengaños y asombros. "iY éste era el gran estadista!" "Y llamaron a toda la América, y se la están arrebatando unos a otros los candidatos rivales, y no calmos en que esto era ni más ni menos que un ardid electoral!" "Ahora me convenzo -dijo en la mesa de adiós un yanquiniano convertido- de que me he pasado los años cazando mariposas". Casi todas las repúblicas, como jadeantes de la última pelea, estaban dándose la mano en torno de una mesa del Shoreham. Se hablaba de prisa, con 
júbilo, en voz baja, como cuando hay nacimiento, como cuando hay boda. Velarde, el dé Bolivia, radiante de gratitud, brindó, entre un coro de copas levantadas, "ipor el héroe del día, por el Bayardo de la conferencia, por el mantenedor inquebrantable de los derechos de los oprimidos y de los débiles, por el autor y el abogado triunfante del proyecto contra la conquista". Y de todos los labios brotaron, como de hijos a padre, palabras de ternura y agradecimiento. Quintana, vencido por primera vez, solo acierta a decir: "iPara mi patria acepto estos cariños!, !Nada más que un pueblo somos todos nosotros en América! !Yo he cumplido, y todos hemos cumplido con nuestro deber!". Un americano sin patria, hijo infeliz de una tierra que no ha sabido inspirar compasión a las repúblicas de que es centinela natural, y parte indispensable, veía, acaso con lágrimas, aquel arrebato de nobleza. Las repúblicas, compadecidas, se volvieron al rincón del hombre infeliz, y brindaron por el americano sin patria. Lo que tomaron unos a piedad y otros a profecía (Schultz, 1968: 112).

Indudablemente, una de las fechas claves en la vida de José Martí fue el 10 de abril de 1892, cuando las emigraciones cubanas y puertorriqueñas, proclamaron el Partido Revolucionario Cubano (P.R.C.), eligiendo a Martí como jefe máximo. A partir de ese momento su actividad es frenética para el partido y la guerra de independencia. Van a ser sentido y fin de su vida, como ocurrió en el combate de Dos Ríos aquel 19 de mayo de 1895, contando para ese entonces 42 años de edad.

No podía morir sino en su patria, aunque no fue testigo fatal del desenlace y futuro de Cuba. Su espíritu libertario es historia y presenta para ese país.

\section{BIBLIOGRAFÍA}

Halperin Donghi, T. (1980): Historia contemporánea de América Latina. Alianza Editorial. Madrid.

Marinello, J. (1977): Cronología. Editorial Ayacucho.

Mestas, J. E. (1993): El pensamiento social de José Martí. Ideología y cuestión obrera. Ed. Pliegos. Madrid.

Schultz De Mantovani, F. (1968): Genio y figura de José Martí. EUDEBA.

\section{Renée Isabel Mengo}

Docente Adjunta en la Cátedra de Historia Social Contemporánea de la Universidad Nacional de Córdoba. Docente Adjunta en la Facultad Regional Córdoba de la Universidad Tecnológica Nacional. Argentina. 